\title{
Physico-Chemical Characteristics and Levels of Preference for Drinking Collagen Drinks the Result of Extracts from Nilem Fish Skins
}

\author{
Junianto Anto*, Iskandar and Achmad Rizal \\ Faculty of Fisheries and Marine Sciences, Department of Fisheries, Padjadjaran University, Indonesia
}

\begin{abstract}
The purpose of this study is to determine the levels and concentration of stabilizers and determine the appropriate levels of sucrose and milk to the level of organoleptic preference for collagen drink products extracted from Nilem fish skin. The study take place in two stages, stage 1 used an experimental method with nine (9) treatments namely xanthan $0.20 \%(\mathrm{~b} / \mathrm{v})$, xanthan $0.25 \%(\mathrm{~b} / \mathrm{v})$, xanthan $0.30 \%(\mathrm{~b} / \mathrm{v}), \mathrm{CMC} 0,20 \%(\mathrm{~b} / \mathrm{v}), \mathrm{CMC} 0.25 \%(\mathrm{~b} / \mathrm{v}), \mathrm{CMC} 0.30 \%$ $(\mathrm{b} / \mathrm{v})$, xanthan-CMC (1: 1) $0.20 \%(\mathrm{~b} / \mathrm{v})$, xanthan -CMC (1: 1) $0.25 \%(\mathrm{~b} / \mathrm{v})$, and xanthan-CMC (1: 1) $0.20 \%(\mathrm{~b} / \mathrm{v})$. Stage 2 used trial method with six (6) treatments namely $5 \%$ sucrose with $0.25 \%(\mathrm{~b} / \mathrm{v})$ skim milk, $5 \%$ sucrose with $0.50 \%$ skim milk (b/v), $10 \%$ sucrose with skim milk $0.25 \%$ (b/v), $10 \%$ sucrose with skim milk $0.50 \%(b / v), 15 \%$ sucrose with $0.25 \%(\mathrm{~b} / \mathrm{v})$ skim milk and $5 \%$ sucrose with skim milk $0.50 \%(\mathrm{~b} / \mathrm{v})$. The stabilizers and concentrations used are the results of the best treatment stage 1 . All experiments are repeated 3 times. The parameters observed in stage 1 are the stability, viscosity and $\mathrm{pH}$ of collagen drinks. The parameters observed in stage 2 are the level of preference for flavor and smell of collagen drinks. Furthermore, the most preferred collagen drinks are observed for their taste and $\mathrm{pH}$. All data is analysed descriptively based on research results showed that the best stabilizer in collagen drinks was xanthan with a concentration of $0.30 \%(\mathrm{~b} / \mathrm{v})$. The viscosity value is $290 \mathrm{mps}$ and $\mathrm{pH}$ is 4.42 . The most preferred collagen drinks by considering the taste and smell were obtained from sucrose treatment $10 \%(\mathrm{~b} / \mathrm{v}) \mathrm{vs}$. skim $0.25 \%$ (b/v). Viscosity and $\mathrm{pH}$ are $297 \mathrm{mPa}$-s and $\mathrm{pH} 5.15$.
\end{abstract}

Keywords: Nilem fish; Collagen; Skin; Drinks; Stability

\section{Introduction}

Collagen extracted from Nilem fish skin is included in type I collagen, with the largest amino acid composition is glycine (16.56\%) [1]. According to Sylviphriya, et al., [2] type I collagen has wide and extensive use in the network engineering industry because of its ability as a high biocompatibility. Bone-forming organic mass consists of $90 \%$ type I collagen. In addition, this type I collagen is also an important component in the tissues of the skin, cornea, tendons and ligaments. According to Hasyim et al., [3] collagen has now been used as an ingredient in foods or drinks intended for diets. This use is caused by the tendency of most people who do not like to include collagen to their body through injections. Collagen is needed to enter the human body because the getting older human body and poor diet can causes collagen production in the body to decrease. The result can affect dehydration, softness and elasticity of the skin. Another impact of the decrease in collagen production in the body is to begin to weaken the binding tissues so that they are susceptible to minor illnesses.

Collagen drinks are included in the functional beverage product group. According to Bilek and Bayram [4] the market share for functional food products including beverages is quite large, for example for Europe at $28.9 \%$, the United States at $31.1 \%$ and Japan at $38.4 \%$. Collagen is widely produced and marketed in beverage products such as cocoa collagen, cappuccino collagen and soy collagen, and the demand for these products tends to increase [3]. In addition, there are also collagen drinks produced by the cosmetic industry that aim to prevent wrinkles and maintain skin moisture [4]. To expand the extraction of extracted collagen from Nilem fish skin, research on the manufacture of collagen drinks was conducted. According to Junianto et al., [1] Nilem fish are Indonesian local fish that have high egg productivity advantages, so that the eggs can be used as raw material for caviar. One of the wastes produced from the processing of Nilem fish eggs into caviar is the skin. This amount of waste is estimated at $10.6 \%$ of the weight of the fish.

Collagen drinks are included in the colloidal system so what needs to be considered is their stability. In addition, the level of consumer acceptance of these drinks is also important to be considered too. Therefore, the purpose of this research is to determine the type and concentration of the appropriate stabilizers to obtain a stable collagen drink product. In addition, it also determines the concentration of sucrose and skim milk in the appropriate collagen beverage formulation to obtain the most preferred collagen beverage products.

\section{Research Methodology}

The ingredients used are collagen extracted from Nilem fish skin, xanthan, Carboxymethyl cellulose (CMC), skim milk, sucrose, food coloring, strawberry flavoring and vitamin C. All these ingredients are obtained from the local market except collagen obtained from the extraction itself. The research took place in two stages, stage 1 the method used was an experiment with nine (9) types of treatment with a concentration of stabilizers to the volume of solvent namely xanthan $0.20 \%(\mathrm{~b} / \mathrm{v})$, xantan $0.25 \%(\mathrm{~b} / \mathrm{v})$, xantan $0.30 \%(\mathrm{~b} / \mathrm{v})$, CMC $0.20 \%(\mathrm{~b} / \mathrm{v})$, CMC $0.25 \%(b / v)$, CMC $0.30 \%(b / v)$, xantan-CMC (1: 1 ) $0.20 \%(b / v)$, Xantan-CMC (1: 1) 0.25\% (b/v), and Xantan-CMC (1: 1) $0.20 \%(\mathrm{~b} / \mathrm{v})$. The solvent used was water for drinks, Stage 2 used an experimental method consisting of six (6) treatment combinations of concentrations between sucrose and skim milk to solvent volume, namely a) $5 \%$ sucrose with $0.25 \%(\mathrm{~b} / \mathrm{v})$ skim milk, $5 \%$ sucrose with skim milk $0.50 \%(\mathrm{~b} / \mathrm{v})$

*Corresponding author: Junianto Anto, Faculty of Fisheries and Marine Sciences, Department of Fisheries, Padjadjaran University, Indonesia, Tel: (022)78801519; E-mail: anto_lisc@yahoo.com

Received October 15, 2018; Accepted December 12, 2018; Published December 15,2018

Citation: Anto J, Iskandar, Rizal A (2018) Physico-Chemical Characteristics and Levels of Preference for Drinking Collagen Drinks the Result of Extracts from Nilem Fish Skin. J Aquac Res Development 9: 555. doi: 10.4172/2155-9546.1000555

Copyright: @ 2018 Anto J, et al. This is an open-access article distributed under the terms of the Creative Commons Attribution License, which permits unrestricted use, distribution, and reproduction in any medium, provided the original author and source are credited. 
$10 \%$ sucrose with $0.25 \%$ (b/v) skim milk, $10 \%$ sucrose with skim milk $0.50 \%(\mathrm{~b} / \mathrm{v})$, sucrose $15 \%$ with $0.25 \%(\mathrm{~b} / \mathrm{v})$ skim milk and $5 \%$ sucrose with $0.50 \%(\mathrm{~b} / \mathrm{v})$ skim milk. The concentration of stabilizers used was the result of the best treatment of stage 1 . All treatments both in stages 1 and 2 are repeated 3 times.

\section{The procedure for stage 1 is as follows [5]:}

Collagen powder extracted from Nilem fish skin weigh $100 \mathrm{mg}$. After that, put in a reaction glass. Then weigh the stabilizer, type and concentration are adjusted to the combination of treatments. Next, the stabilizer is put into a bottle that contains collagen powder. The last step is to add $10 \mathrm{ml}$ of drinking water that has been given a food coloring agent $(0.01 \%,(\mathrm{v} / \mathrm{v}))$ and strawberry flavoring $(0.01 \%,(\mathrm{v} / \mathrm{v})$ as much as $10 \mathrm{ml}$ into the reaction glass that has been contained collagen and stabilizer, then stirred quickly until homogeneous with vortex for 10 minutes, then stored in the bottle for 10 days in cold $\left(4-10^{\circ} \mathrm{C}\right)$. On day $0,1,3,5,7,9$ and 11 observed phase separation ratios. Calculation of colloidal stability based on Febrina 2007 method, namely the percentage ratio between separate phase height and high dispersion of the initial solution. Other observations were solution viscosity (with Brookfield viscometer) and $\mathrm{pH}$ (with $\mathrm{pH}$ meter) observed when the solution was formed which happened on day 0 . The experiment was repeated 3 times, the data obtained from all the parameters were analyzed descriptively.

\section{For procedure stage 2 is as follows [5]:}

Collagen powder extracted from Nilem fish skin weigh as much as $100 \mathrm{mg}$. After that, put it in the reaction glass. Then weigh xanthan stabilizer as much as $30 \mathrm{mg}(0.30 \%)$ (based on the best treatment results from experiment 1 ) and put it into a reaction glass that has collagen. Then weigh sucrose and skim milk according to the treatment and then put it into a reaction glass that had collagen and xanthan powder. Then a drinking water solvent was added which had been given a food coloring agent $(0.01 \%,(\mathrm{v} / \mathrm{v}))$ and strawberry flavoring $(0.01 \%,(\mathrm{v} / \mathrm{v})$ as much as $10 \mathrm{ml}$. The final step was homogenized by using vortex for about 10 minutes, then the collagen drink was observed for its organoleptic preference for taste and the smell by 15 semi-trained panelists, and the most preferred collagen drink was measured by its viscosity and $\mathrm{pH} 3$ = dislike, 5 = ordinary, 7 = like and $9=$ very like, the experiment was repeated 3 times, all the data obtained were analyzed descriptively.

\section{Results and Discussion}

\section{Stability of collagen drinks dispersion}

Liquid collagen drinks are included in dispersion or suspension systems. According to Diubinski et al., [6] in the dispersion system there are two phases, namely the continuous phase and the dispersion phase. The continuous phase is liquid, while the dispersion phase is solid particles. In this collagen drink research, the continuous phase is water and its dispersion phase is collagen and skim milk. The main key in this dispersion system is the stability of the system, and one of the factors that influence the level of stability is the type and concentration of stabilizers used [7]. The results of observations on the level of stability of collagen drinks from various types of treatments and concentration of stabilizers as shown in Table 1.

The treatment of xanthan as a stabilizing agent at a concentration of $0.30 \%$ from the continuous phase of the collagen drink gave the best level of dispersion stability compared to other treatments (Table 1). The percentage of stability is $100 \%$ and lasts up to 11 days at room temperature. The use of CMC stabilizers at a concentration of $0.30 \%$ in collagen drinks showed that at the first day of storage deposition had occurred. This shows that the use of xanthan as a stabilizer is better than CMC. Similar results were also reported by Marfu'ah and Sutaryono [8], the use of xanthan as a stabilizer was better than CMC on the physical stability of chloramphenicol suspension. Akkarachaneeyakom and Tinrat [9] also reported that the use of xantan gives the stability results of mulbery fruit juice that is better than CMC.

\section{Viscosity of collagen drinks}

The viscosity of the drink is crucial for the level of consumer acceptance. Viscosity determines the ease with which a molecule moves because of the frictional forces between material layers, in the case of liquid substances due to cohesion forces [10]. The results of the viscosity measurements of collagen drinks in the treatment of various stabilizers with certain concentrations are shown in Table 2.

Collagen drinks that have the highest viscosity values were obtained from xanthan stabilizer treatment with a concentration of $0.30 \%(290$ mPa-s) (Table 2). This shows that collagen drinks resulting from the treatment are the most viscous compared to other treatments. This research is in line with research conducted by Akkarachaneeyakom and Tinrat [9], that the use of zanthan stabilizing agent gives a higher viscosity value $(422.11 \mathrm{mPa}-\mathrm{s})$ at the same concentration $(0.5 \%)$ than CMC (281, $33 \mathrm{mPa}-\mathrm{s})$ on mulbery fruit juice drinks. According to Diubinski et al., [6], the high viscosity of a suspension is guaranteed to have good stability.

According to Akkarachaneeyakom and Tinrat [9], xanthan is a branched hydrocolloid which has many branches and the branches are very long compared to other hydrocolloids. As a result, xanthan in a suspension can form many hydrogen bonds so as to increase suspension viscosity. The more hydrogen bonds are formed in a suspension, the higher the viscosity.

\section{$\mathrm{pH}$ of collagen drinks}

The $\mathrm{pH}$ value of the beverage is very important to know because it will have an impact on dental health, acidic drinks will accelerate the softening of the tooth structure or erosion of the tooth surface [11]. The results of the measurement of the $\mathrm{pH}$ value of collagen drinks from the treatment of various stabilizers with certain concentrations are shown in Table 2.

The $\mathrm{pH}$ value of collagen drinks based on Table 2 above ranges from 4.42-4.492. According to Larsen and Nyvad [12], drinks that have a pH value above 4 will have a minimal impact on tooth erosion. Drinks with very acidic $\mathrm{pH}$ (lower than 3 ) provide a high level of tooth erosion.

Collagen drinks pruduct of this research which had the lowest $\mathrm{pH}$ were obtained from the treatment of xanthan stabilizers with a concentration of $0.3 \%$ while the highest was obtained from the treatment of CMC stabilizers with a concentration of $0.3 \%$ (Table 2). The results of the study reported by Marfu'ah and Sutaryono [8] also concluded that the use of xanthan in a suspension gives a lower $\mathrm{pH}$ than CMC. This is because xanthan is more acidic than CMC. According to Desplanques et al., [13], xanthan is an anionic exocellular polysaccharide produced fermentatively from sugar (sugars) aerobics by Xanthomas campestris bacteria, this product is acidic. Whereas CMC is anionic polyeletrolite derived from cellulose with alkaline treatment and sodium salt, carboxyl group is alkaline [14].

\section{Level of preference for collagen drinks}

In order to improve the taste of collagen drinks, development was carried out by adding sucrose and skim. Collagen drinks developed 
Citation: Anto J, Iskandar, Rizal A (2018) Physico-Chemical Characteristics and Levels of Preference for Drinking Collagen Drinks the Result of Extracts from Nilem Fish Skin. J Aquac Res Development 9: 555. doi: 10.4172/2155-9546.1000555

Page 3 of 4

\begin{tabular}{|c|c|c|c|c|c|c|c|}
\hline \multirow{2}{*}{$\begin{array}{l}\text { Treatment of stabilizers with certain } \\
\text { concentration }\end{array}$} & \multicolumn{7}{|c|}{ Day of storage } \\
\hline & 0 & 1 & 3 & 5 & 7 & 9 & 11 \\
\hline Xanthan $0.20 \%(\mathrm{~b} / \mathrm{v})$ & 100 & 92.5 & 84.3 & 79.5 & 77.2 & 76.6 & 74.1 \\
\hline Xanthan $0.25 \%(b / v)$ & 100 & 100 & 100 & 100 & 100 & 98.8 & 90.5 \\
\hline Xanthan $0.30 \%(b / v)$ & 100 & 100 & 100 & 100 & 100 & 100 & 100 \\
\hline CMC $0.20 \%(b / v)$ & 100 & 39.1 & 28.7 & 25.7 & 24.3 & 21.8 & 20.9 \\
\hline CMC $0.25 \%(b / v)$ & 100 & 39.1 & 31.1 & 28.4 & 27.9 & 25.9 & 24.5 \\
\hline CMC $0.30 \%(b / v)$ & 100 & 78.0 & 51.1 & 40.1 & 36.8 & 33.5 & 33.0 \\
\hline Xanthan-CMC (1:1). $0.20 \%$ & 100 & 96.4 & 75.4 & 67.7 & 62.7 & 61.2 & 61.2 \\
\hline Xanthan-CMC (1:1). 0.25\% & 100 & 100 & 88.6 & 82.7 & 77.5 & 74.9 & 74.9 \\
\hline Xanthan-CMC (1:1). 0.30\% & 100 & 100 & 96.4 & 93.9 & 91.1 & 91.1 & 91.1 \\
\hline
\end{tabular}

Table 1: Average stability (\%) of collagen drinks during storage (days).

\begin{tabular}{|c|c|c|}
\hline Treatment of stabilizers with certain concentration & Average Viscosity (mPa-s) & 175 \\
\hline Xanthan $0.20 \%(b / v)$ & 275 \\
\hline Xanthan $0.25 \%(b / v)$ & 290 & 4.42 \\
\hline Xanthan $0.30 \%(b / v)$ & 120 & 4.40 \\
\hline CMC $0.20 \%(b / v)$ & 125 & 4.35 \\
\hline CMC $0.25 \%(b / v)$ & 140 & 4.94 \\
\hline CMC $0.30 \%(b / v)$ & 155 & 4.97 \\
\hline Xanthan-CMC (1:1). 0.20\% & 180 \\
\hline Xanthan-CMC (1:1). 0.25\% & 235 \\
\hline
\end{tabular}

Table 2: Average viscosity values and $\mathrm{pH}$ of collagen drinks in the treatment of various stabilizers with a certain concentration.

\begin{tabular}{|c|c|c|}
\hline Treatment of sucrose and skim concentration & Average value of taste preference level & Average value of smell preference level \\
\hline Sucrose $5 \%(b / v)$ vs skim $0.25 \%(b / v)$ & 6.8 \\
\hline Sucrose $5 \%(b / v)$ vs skim $0.50 \%(b / v)$ & 6.2 \\
\hline Sucrose $10 \%(b / v)$ vs skim $0.25 \%(b / v)$ & 7 \\
\hline Sucrose $10 \%(b / v)$ vs skim $0.50 \%(b / v)$ & 6.8 \\
\hline Sucrose $15 \%(b / v)$ vs skim $0.25 \%(b / v)$ & 6.4 \\
\hline Sucrose $15 \%(b / v)$ vs skim $0.50 \%(b / v)$ & 5.6 \\
\hline
\end{tabular}

Table 3: Average values of taste and smell preference from collagen drinks in various treatments of sucrose and skim concentrations.

were derived from the treatment results of addition of xanthan stabilizers with a concentration of $0.3 \%$. The results of the hedonic test (preference) of these collagen drinks are in Table 3.

Based on Table 3, panelist's preference for collagen drinks from all treatments of adding sucrose and skim averages ranged from normal/ neutral (5) to liking (7) both for taste and smell. The highest level of taste and smell preference of collagen drinks was obtained from the treatment of $10 \%$ sucrose addition with $0.25 \%$ skim. Panelists like the product because the sweetness level is right (not too sweet) with a not too "fishy" smell. The panelist also commented that the more sucrose added it tastes sweeter and the more skim added the smell smells "fishy". According to Ventura et al., [15], currently many consumers like drinks that are not too sweet to avoid the risk of fatty liver disease, obesity, cardiovascular disease, and diabetes.

Furthermore, the panelists commented to prioritize the taste rather than smell in choosing collagen drinks. 10 out of 15 panelists (67\%) preferred to prioritize the taste than smell. Masri [16] informs that teenager's preference for drinks, taste $(68.4 \%)$ is more important than other atribute.

Characteristics of collagen drinks from the preferred formulation (sucrose $10 \%(\mathrm{~b} / \mathrm{v})$ vs. skim $0.25 \%(\mathrm{~b} / \mathrm{v})$ have a viscosity value of $297 \mathrm{mPa}-\mathrm{s}$ and a $\mathrm{pH}$ of 5.15 . This viscosity and $\mathrm{pH}$ value is higher compared to pre-added collagen drinks plus sucrose and skim (Table 2). The increase in viscosity and $\mathrm{pH}$ is caused by the addition of sucrose. According to Silviera et al., [17], sucrose is commonly used as a sweetener for soft drinks and is also used as an acid level controller. affected by its concentration and temperature, the higher the concentration the higher the viscosity [18].

\section{Conclusion}

Based on research results, the best stabilizer in collagen drinks is xanthan with a concentration of $0.30 \%(b / v)$. The viscosity value is 290 $\mathrm{mps}$ and $\mathrm{pH}$ is 4.42 . The most preferred collagen drinks by considering the taste and smell were obtained from sucrose treatment $10 \%(\mathrm{~b} / \mathrm{v}) \mathrm{vs}$. skim $0.25 \%(\mathrm{~b} / \mathrm{v})$. Viscosity and $\mathrm{pH}$ are $297 \mathrm{mPa}$-s and $\mathrm{pH} 5.15$.

\section{Acknowledgments}

Acknowledgments were conveyed to the Directorate General of Strengthening Research and Development, Ministry of Research, Technology and Higher Education for the funds provided based on Decree Number 01/E/KPT/2018 and Agreement/Contract Number 599/UN6.M/LT/2018, February 6, 2018. In addition acknowledgments were given to the Director of Research and Community Service at Padjadjaran University, which facilitated this research. Acknowledgments were also made to Sriningsih, Mutiara and Elang for the assistance in this research.

\section{References}

1. Junianto A, Iskandar I, Rizal A (2018) Characteristics of physical-chemical properties of collagen extracted from the skin of bonylip barb fish (Osteochilus vittatus). World Appl Sci J 36: 78-84.

2. Silvipriya KS, Kumar KK, Bhat AR, Kumar BD, John A, et al. (2015) Collagen Animal sources and biomedical application. J Appl Pharm Sci 5: 123-127. 
Citation: Anto J, Iskandar, Rizal A (2018) Physico-Chemical Characteristics and Levels of Preference for Drinking Collagen Drinks the Result of Extracts from Nilem Fish Skin. J Aquac Res Development 9: 555. doi: 10.4172/2155-9546.1000555

3. Hashim P, Ridzwan M, Bakar J, Hashim M (2015) Collagen in food and beverage industries. Int Food Res $\mathrm{J}$ 22: 1-8

4. Bilek SE, Bayram SK (2015) Fruit juice drink production containing hydrolyzed collagen. J Funct Foods 14: 562-569.

5. Lawang AT (2013) Making dispersion of cork fish concentarate for supplementary food. Skripsi, Fakultas Pertanian Universitas Hasanuddin, Makasar, Indonesia.

6. Diubinski M, Witczak-Stawicka A, Stawczyk J (2004) Study of suspension stability. Petrol Coal 46: 47-54.

7. Larson M, Hill A, Duffy J (2012) Suspension stability; why particle size, zeta potensial and rheology are important. Annual trans Nordic Rheol 20: 209-214.

8. Dan Sutaryono MA (2011) Differences in carboxymethyl cellulosa and xanthan gum as suspending agent to the physical stability of chlramphenicol suspension. J Health Sci 6: 1-17.

9. Akkarachaneeyakom S, Tinrat S (2015) Effects of types amd amount of stabilizer on physical anzd sensory charateristics of cloudy ready-to-drink mulberry fruit juice. Food Sci Nutrn 3: 213-220.

10. Ningrum SK, Toifur M (2014) Determination of sugar solution viscosity using vessel connected with a viscometer method based on video based laboratory with software tracker. Jurnal Riset dan Kajian Pendidikan Fisika 1: 57-62.
11. Reddy A, Norris DF, Momeni SS, Waldo B, Ruby JD (2016) The pH of beverages in the United States. J Am Dent Assoc 147: 255-263.

12. Larsen MJ, Nyvad B (1999) Enamel erosion by some soft drinks and orange juices relative to their $\mathrm{pH}$, buffering effect and contents of calcium phosphate. Caries Res 33: 81-87.

13. Desplanques S, Renou F, Grisel M, Malhiac C (2012) Impact of chemical composition of xanthan and acacia gum on the emulsification and stability of oil-in-water emulsions. Food Hydrocol 27: 401-410.

14. Anggraini DN, Radiati LE, Purwadi P (2016) Carboxymethyle Cellulose (CMC) addition in term of taste, aroma, color, $\mathrm{pH}$,viscosity, and turbidity of apple cider honey drink. J Ilmu dan Teknologi Hasil Ternak 11: 58-67.

15. Ventura EE, Davis JN, Goran MI (2011) Sugar content of popular sweetened beverages based on objective laboratory analysis: A focus on fructose content. Obesity 19: 868-874

16. Masri E (2018) Determinant factor in treatment of high-calorie beverages consumption in students. Sientia 8: 53-63.

17. Silviera L, Moreira LM, Conceicao VGB, Casalechi HL, Munoz IS, et al. (2009) Determination of sucrose concentration in lemon-type soft drinks by dispersive Raman spectroscopy. Spetrocopy 23: 217- 226.

18. Tellis VRN, Telis-Romero J, Mazzotti HB, Gabas AL (2007) Viscosity of aqueous carbohydrate solutions at different temperature and concentratios. Int $\mathrm{J}$ Food Prop 10: 185-195. 